\title{
Evaluating the relationship between nasal obstruction and Mean Platelet Volume by using acoustic rhinometry in patients with septum deviation*
}

\author{
Şahin Ulu' ${ }^{1}$ M. Sena Ulu², Abdulkadir Bucak' , O. Kemal Kahveci', \\ Fatih Yücedağ', Abdullah Ayçiçek' \\ 1 Department of Otorhinolaryngology, Afyon Kocatepe University, Faculty of Medicine, Afyonkarahisar, Turkey. \\ 2 Department of Internal Medicine, Afyon Kocatepe University Faculty of Medicine, Afyonkarahisar, Turkey
}

Rhinology 51: 249-252, 2013

DOI:10.4193/Rhino12.169

*Received for publication:

October 2, 2012

Accepted: February 21, 2013

\begin{abstract}
Summary
Background: Nasal airway obstruction is a common cause of upper airway obstruction. It is associated strongly with obstructive and hypoxic manifestations. Mean platelet volume (MPV) levels increase in hypoxic conditions. MPV is one of the platelet activation indices which reflects the platelet production rate. We aimed to evaluate the relationship between MPV levels and nasal septal deviation (NSD) by using acoustics rhinometry in patients with septum deviation.
\end{abstract}

Methods: We performed a retrospective study of 51 patients with NSD and 58 healthy age matched subjects as control group. The diagnosis of patients with NSD was based on anterior rhinoscopy, endoscopic nasal examination and acoustics rhinometry. All the patients underwent Cottle- or Killian-type septoplasty under general anesthesia. Blood samples were collected before nasal septoplasty.

Results: MPV and platelet distribution width (PDW) levels were significantly higher and mean platelet count was lower in patients with NSD than the control group. A negative correlation was found between MPV, NDVol2 (volume2 of non-deviated side of the nose) and TNDVol (total volume of non-deviated side of the nose) values.

Conclusion: MPV values increase in patients with NSD. Moreover, this increase was found in relation with the severity of obstruction.

Key words: nasal septum deviation, Mean Platelet Volume, acoustics rhinometry

\section{Introduction}

Nasal airway obstruction due to septal deviation is a common complaint of patients presenting to otorhinolaryngology clinics. It should be considered in the differential diagnosis of hypoxemia.

Nasal septal deviation is a major cause of nasal obstruction. The problems causing upper airway obstruction such as adenoid vegetation, hypertrophied tonsils, nasal polyposis, and septal deviation can lead to chronic hypoxia and many cardiovascular complications such as alveolar hypoventilation, cor pulmonale, and pulmonary hypertension ${ }^{(1-4)}$.

The relationship between diseases causing hypoxia and platelet activation has been shown in many studies ${ }^{(5,6)}$. In parallel with this, MPV levels increase in hypoxic conditions ${ }^{(7,8)}$.

Mean platelet volume (MPV) is a parameter as part of routine complete blood count tests and it is one of the platelet function 
indices and which reflects the platelet production rate, stimulation, activation and aggregation ${ }^{(9-11)}$. It is known that larger platelets are more adhesive and likely to aggregate than small ones ${ }^{(12)}$.

In the previous study, it was shown that, MPV values increase in septal deviation. But, according to our knowledge, MPV values in septal deviation has not been investigated by using acoustics rhinometry, which is a diagnostic technique used to assess the geometry of the nasal cavity and nasopharynx, providing in this way information about possible nasal obstruction.

Based on this background, the first aim of this study is to investigate the relationship between septal deviation and MPV, and the second is to evaluate the relationship between the acoustic rhinometry outcomes and MPV values.

\section{Material and methods}

This study was conducted in Afyon Kocatepe University, School of Medicine Hospital between January 2007 and January 2012.

\section{Study population}

Fifty one patients who were admitted to the otorhinolaryngology department and diagnosed with nasal septal deviation were enrolled in the study. Results were compared with 58 agematched, healthy control subjects.

The diagnosis of the patients with septal deviation was based on anterior rhinoscopy and endoscopic nasal examination. Acoustic rhinometry was performed to all patients preoperatively. All the patients underwent Cottle- or Killian-type septoplasty while under general anesthesia. Blood samples were collected before nasal septoplasty.

Patients, with, systemic disease such as any known cardiac and lung disease, angina pectoris, arrhythmias, diabetes mellitus, chronic renal or hepatic diseases, haematological disease, cancer, thrombocytopenia, hypothyroidism and hyperthyroidism, autoimmune disease, antithrombotic agent or serotonin reuptake inhibitor drug use, chronic or systemic inflammatory diseases such as bronchial asthma, rheumatoid arthritis, psoriasis, inflammatory bowel disease, and allergic rhinitis, inferior turbinate hypertrophy, nasal polyposis, smoking history, serum electrolyte imbalance and pre-operative infection were excluded from the study. Informed written consent was obtained from all subjects. None of the subjects were on aspirin or other antiagregant therapy. The control group was composed of healty subjects without smoking or allergic rhinitis history who were admitted to the internal medicine department.

\section{Acoustics rhinometry measurements}

Nasal cavities were cleaned and prepared for acoustic rhinometry. Acoustic rhinometry (Rhinometrics, Denmark) measurements were performed 10 minutes after applying nasal decongestant xylometazolin 0.01\% (Iliadin spray, Santa Farma, Istanbul, Turkey) in a relatively quiet room at normal temperature and humidity $(40 \% \pm 15.3)$ to eliminate the mucosal oedema or concha hypertrophy. Minimal cross section area at the first $2 \mathrm{~cm}$ (MCA1) and between the $2 \mathrm{nd}$ and 5 th $\mathrm{cm}$ of nasal cavity (MCA2), and nasal cavity volume at the first $2 \mathrm{~cm}$ (Vol1) and between the $2 \mathrm{nd}$ and 5 th $\mathrm{cm}$ (Vol2) were separately recorded for the deviated and non-deviated side of the nose. The sum of Vol1 and Vol2 was accepted as total volume of associated side of the nasal cavity. The sum of MCA1 and MCA2 was accepted as total area of associated side of the nasal cavity.

\section{Physical examination}

All subjects with septal deviation underwent physical examination. Nasal passages, nasopharynx, oropharynx and laryngeal examination was performed by a flexible fiberoptic endoscope (Karl Storz 11101 VP, Germany).

Biochemical and hematological analyses MPV, platelet distribution width (PDW), Platelet count (PC), $\mathrm{Hb}$, $\mathrm{Htc}$ and Red Blood Cell counts (RBC) in blood samples were measured before the treatment. Initially, patients with abnormal findings in fasting glycemia, creatinine, total cholesterol and fractions, triglycerides and TSH were excluded.

Venous blood samples for haemograms were collected into tubes containing ethylene-diamine-tetraacetic acid (EDTA) at 8 a.m. following an overnight fast. To avoid platelet swelling, MPV and PDW were measured in the blood samples between 15-30 min after sampling. An automated blood cell counter was used for these measurements (Sysmex XT 2000i, Kobe, Japan). All samples were run in duplicate, and the mean values were used for statistical analysis.

\section{Statistical analysis}

The data were summarized using descriptive statistics. Chi-square test and Student's t tests (independent sample t test) were used to compare the groups. Spearman correlation analysis was used to explore the relationship between septal deviation and others parameters. A $\mathrm{p}<0.05$ was accepted as significant.

\section{Results}

The Male/Female ratio of patients with septal deviation was $41 / 10$ and the Male/Female ratio of the control group was 24/34. Mean age of patients with septal deviation was $34.2 \pm 13.8$ years and that of the control group was $36.1 \pm 10.8$ years.

Mean $\mathrm{Hb}, \mathrm{Htc}$ and RBC values of the patients with septal deviation were significantly higher than the control group $(p<0.001)$, $(p<0.001),(p=0.013)$, respectively (Table 1$)$.

Mean MPV values of septal deviation patients were $10.2 \pm 0.7 \mathrm{fl}$ 
Table 1. Mean age and hematologic parameters of the NSD patients and the control group.

\begin{tabular}{|lccc|}
\hline Variables & Control Group & Patient Group & p \\
\hline Age (year) & $36.1 \pm 10.8$ & $34.2 \pm 13.8$ & NS \\
\hline MPV (fl) & $9.5 \pm 0.4$ & $10.2 \pm 0.7$ & $<0.001$ \\
\hline PDW (fl) & $11 \pm 0.9$ & $12.4 \pm 1.5$ & $<0.001$ \\
\hline Platelet counts/u & $286.8 \pm 62.3$ & $232 \pm 44.9$ & $<0.001$ \\
\hline RBC (10\%/mm $)$ & $4.9 \pm 0.4$ & $5.1 \pm 0.3$ & 0.013 \\
\hline Hb (g/dl) & $14.1 \pm 1.8$ & $15.4 \pm 1.0$ & $<0.001$ \\
\hline Htc (\%) & $41.8 \pm 4.3$ & $44.9 \pm 2.8$ & $<0.001$ \\
\hline
\end{tabular}

All parameters were expressed as mean \pm standard deviation unless otherwise stated. $p<0.05$ value was accepted as significant level and the significant differences between the groups were shown in bold. NS: not significant.

and the control group's were $9.5 \pm 0.4 f$. Mean MPV values in patients with septal deviation were significantly higher than the control group $(p<0.001)$.

Mean PDW values of patients were $12.4 \pm 1.5 \mathrm{fl}$ and the control group's were $11 \pm 0.9 \mathrm{fl}$. Mean PDW values in patients with septal deviation were significantly higher than the control group $(p<$ 0.001).

Mean platelet count of septal deviation patients were 232.7 $\pm 44.9 / \mathrm{u}$ and the control group's were $286.8 \pm 62.3 / \mathrm{u}$. Mean platelet count values in patients with septal deviation were significantly lower than the control group ( $<<0.001)$.

In the correlation analysis, a negative correlation was found between MPV and Non Deviated Side Volume 2, Non Deviated Side Total Volume values $(r=-0.285 ; p=0.04) ;(r=-286 ; p=0.04)$, respectively. The relationship between MPV and Non Deviated Side Volume 2 is shown in Figure 1.

The characteristics, MPV, PDW values and platelet counts of the septal deviation patients and the control group are outlined in Table 1.

\section{Discussion}

This study evaluated the relationship of nasal obstruction and MPV by using acoustics rhinometry. In our study, MPV and PDW levels in patients with septal deviation were found to be significantly higher than in the control group. Additionally, a negative correlation was found between MPV and Non Deviated

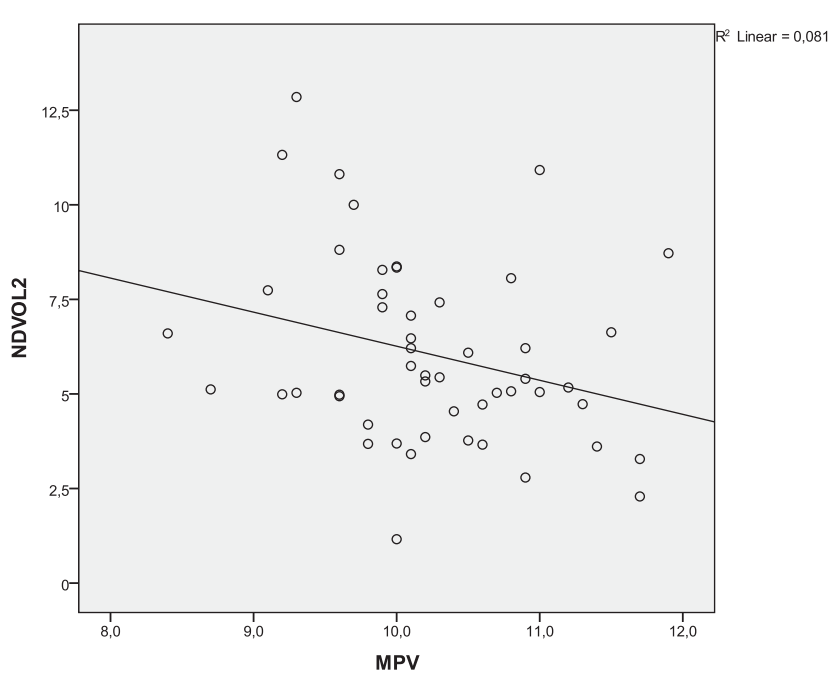

Figure 1. The relationship between Mean Platelet Volume and NondeviatedVolume2

Side Volume 2 and Non Deviated Side Total Volume. This may mean that the decrease of Non Deviated Side Volume 2 and Non Deviated Side Total Volume causes more hypoxia than the other regions as indicated by the increased MPV.

Nasal septal deviation, which is an anatomical finding that may potentially lead to nasal obstruction, is a common complaint of patients presenting to otorhinolaryngology clinics. It may being overlooked sometimes but it is an important condition because of its possible complications such as alveolar hypoventilation, cor pulmonale, and pulmonary hypertension ${ }^{(1,3,4)}$.

It should be considered in the differential diagnosis of chronic hypoxia. In the present study, Hb, Htc and RBC levels of the patients with septal deviation were higher than the control group in parallel with the literature due to hypoxia-induced erythropoiesis ${ }^{(13)}$.

It has been shown that chronic hypoxia is associated with many cardiovascular complications as a result of hypercoagulopathy via platelet activation ${ }^{(5,6,14,15)}$. Elevated serum IL-6 levels, which can lead to the increased production of more active and larger platelets, have been shown in patients with chronic hypoxia ${ }^{(16)}$. In parallel with more active and larger platelets, MPV levels increase ${ }^{(7,8)}$. Therefore this may be the explanation of why MPV levels are increasing in chronic hypoxic conditions like upper airway obstruction and obstructive sleep apnea syndrome ${ }^{(8,17)}$.

Mean platelet volume (MPV) is one of the platelet activation indices which reflects the platelet production rate, stimulation, 
activation and aggregation ${ }^{(9)}$. It is known that larger platelets are more adhesive and likely to aggregate than small ones ${ }^{(10)}$. It is one of the most widely used surrogate markers of platelet function today ${ }^{(11,12)}$.

In a recent study, Sagit et al. found increased coagulation in patients with septum deviation and they concluded that this result was due to chronic hypoxia and hypercarbia and increased MPV levels were the best indicator of this because of its increasing levels according to severity of the obstruction ${ }^{(4)}$.

Based on our study, it can be considered that MPV values may be an indicator of obstruction and hypoxia in patients with septal deviation and this may be helpful for us to give an operation decision to prevent cardiovascular complications due to septal deviation.

As a conclusion, MPV is a parameter that should be part of routine complete blood count tests, but which is usually overlooked by clinicians. It is increasing in nasal obstruction and may used to determine the obstruction in septal deviation. One should therefore be careful about evaluating MPV values.

\section{Author contribution}

All authors have contributed during the study and the writing stage.

\section{Conflict of interest}

There is no conflict of interest.

\section{References}

1. Fidan V, Aksakal E. Impact of septoplasty on pulmonary artery pressure in patients with markedly deviated septum. J Craniofac Surg. 2011; 22: 1591-1593

2. Brodsky L, Poje C. Tonsillitis, Tonsillectomy and Adenoidectomy. In: Bailey JB, Calhoun KH, Deksin RW, eds. Head and Neck Surgery-Otolaryngology. Philadelphia: Lippincott-Raven Press, 1998; 1221-1235.

3. Simon P, Sidle D. Augmenting the nasal airway: Beyond septoplasty. Am J Rhinol Allergy. 2012; 26: 326-331

4. Sagit M, Korkmaz F, Kavugudurmaz M, Somdas MA. Impact of septoplasty on mean platelet volume levels in patients with marked nasal septal deviation. J Craniofac Surg. 2012; 23: 974-976.

5. Liak C, Fitzpatrick M. Coagulability in obstructive sleep apnea. Can Respir J. 2011; 18: 338-348.

6. Lui MM, Sau-Man M. OSA and atherosclerosis. J Thorac Dis. 2012; 1: 164-172.

7. Rahangdale S, Yeh SY, Novack V, et al. The influence of intermittent hypoxemia on platelet activation in obese patients with obstructive sleep apnea. J Clin Sleep Med. 2011; 15;7: 172-178.

8. Varol E, Ozturk O, Gonca T, et al. Mean platelet volume is increased in patients with severe obstructive sleep apnea. Scand J Clin Lab Invest. 2010; 70: 497-502.

9. Briggs C. Quality counts: New parameters in blood cell counting. IntJ Lab Hematol. 2009; 31: 277-297.

10. Kapsoritakis AN, Koukourakis MI, Sfiridaki A, et al. Mean platelet volume: a useful marker of inflammatory bowel disease activity. Am J Gastroenterol. 2001; 96: 776-781.

11. Kisacik B, Tufan A, Kalyoncu U. Mean platelet volume (MPV) as an inflammatory marker in ankylosing spondylitis and rheumatoid arthritis. Joint Bone Spine. 2008; 75: 291294.

12. Schoene NW. Design criteria: tests used to assess platelet function. Am J Clin Nutr. 1997; 65: 1665S-1668S.

13. Khan AM, Ashizawa S, Hlebowicz V, Appel DW. Anemia of aging and obstructive sleep apnea. Sleep Breath. 2011; 15: 29-34.

14. Olson EJ, Park JG, Morgenthaler TI. Obstructive sleep apnea-hypopnea syndrome. Prim Care. 2005; 32: 329-359.

15. Von Kanel R, Dimsdale JE. Hemostatic alterations in patients with obstructive sleep apnea and the implications for cardiovascular disease. Chest. 2003; 124: 1956-1967.

16. Nena E, Papanas N, Steiropoulos P, et al. Mean Platelet Volume and Platelet Distribution Width in non-diabetic subjects with Obstructive Sleep Apnoea Syndrome: New indices of severity? Platelets. 2012; 23: 447-454.

17. Debili N, Masse JM, Katz A, Guichard J, Breton-Gorius J, Vainchenker W. Effects of the recombinant hematopoietic growth factors interleukin-3, interleukin-6, stem cell factor, and leukemia inhibitory factor on the megakaryocytic differentiation of CD34s cells. Blood. 1993; 82: 84-95.

Sahin Ulu, MD

Department of Otorhinolaryngology

School of Medicine

University of Afyon Kocatepe

Afyonkarahisar

Turkey 03200

Tel: +90-272-246 3321

Fax: +90-272-213 3066

E-mail: drsahinulu@yahoo.com 